\title{
EFECTO DEL 1-METILCICLLOPROPENO EN LA MADURACIÓN DE MANGO ATAULFO EN CONDICIÓN SIMULADA PARA EXPORTACIÓN A EUROPA
}

\section{EFFECT OF 1-METHYLCYCLOPROPENE ON ATAULFO MANGOE MATURATION UNDER SIMULATED CONDITIONS FOR EXPORT TO EUROPE}

\author{
Loretta Z. Ortiz-Franco', Anaid Z. Ramírez-Villa', Lilian J. Cervantes-Mojica', \\ Ma. Dolores Muy-Rangel ${ }^{2}$, Miguel A. Gómez-Lim³ ${ }^{3}, H$. Sergio García-Galindo ${ }^{4}$, \\ Sonia G. Sáyago-Ayerdi ${ }^{1}$ y Efigenia Montalvo-González ${ }^{1}$ *
}

\begin{abstract}
'Laboratorio Integral de Investigación en Alimentos, Posgrado en Ciencias en Alimentos, Instituto Tecnológico de Tepic. Av Tecnológico No. 2595. 63175, Fracc. Lagos del Country. Tepic, Nayarit. México. ${ }^{2}$ Centro de investigación en Alimentación y Desarrollo, A.C.Km. 5.5 Carr. A Eldorado. 80110 Colonia Campo el Diez, Culiacán, Sinaloa. ${ }^{3}$ Centro de Investigación y de Estudios Avanzados-Unidad Irapuato. Km. 9.6 Libramiento Norte Carr. Irapuato-León. 36821, Irapuato Gto. ${ }^{4}$ Unidad de Investigación y Desarrollo en Alimentos, Instituto Tecnológico de Veracruz, Calz. Miguel Ángel de Quevedo 2779. 91897, Veracruz, Veracruz.
\end{abstract}

*Autor de correspondencia (efimontalvo@gmail.com)

\section{RESUMEN}

El objetivo de esta investigación fue evaluar el efecto del 1-metilciclopropeno (1-MCP) en el proceso de maduración y calidad de mango (Mangifera indica L.) var. Ataulfo almacenado $20 \mathrm{~d} \mathrm{a} 13^{\circ} \mathrm{C}$ y $5 \mathrm{~d}$ a $25^{\circ} \mathrm{C}$, que simulan el transporte y distribución en Europa, para generar conocimiento sobre la acción del 1-MCP en el metabolismo del etileno; así como para encontrar condiciones de aplicación de 1-MCP en esta variedad. Los frutos fueron tratados con 1-MCP $\left(0,300,600\right.$ y $\left.1000 \mathrm{~nL} \mathrm{~L}^{-1}\right)$ con y sin tratamiento hidrotérmico (CH y SH). Se midió la velocidad de respiración (VR), producción de etileno (VPE), contenido de ácido aminociclopropano-1-carboxílico (ACC), actividad de ACC oxidasa, transcritos (receptor ETR1 de etileno y ACC oxidasa ACO), variables físicas y químicas. En los frutos testigo $\mathrm{SH}$ y $\mathrm{CH}$, la máxima VR fue de 129.12 y 129.37 $\mathrm{mL} \mathrm{CO} \mathrm{kg}^{-1} \mathrm{~h}^{-1}$ (días 1 y 4 a $25^{\circ} \mathrm{C}$ ), respectivamente; la VPE fue de 0.15 y $0.23 \mu \mathrm{Lg}^{-1} \mathrm{~h}^{-1}$. La VR se redujo en los frutos SH con 1-MCP $\left(86.17 \mathrm{~mL} \mathrm{CO}_{2}\right.$ $\left.\mathrm{kg}^{-1} \mathrm{~h}^{-1}\right)$, así como se redujeron la VPE $\left(0.13 \mu \mathrm{L} \mathrm{kg}^{-1} \mathrm{~h}^{-1}\right)$, la actividad de la ACC oxidasa y la expresión de los genes ETR1 y ACO después de su traslado a 25 ${ }^{\circ} \mathrm{C}$ (4 a $5 \mathrm{~d}$ ). En los frutos $\mathrm{CH}$ y con 1-MCP no se observaron estos cambios. Los mangos SH con $1000 \mathrm{~nL} \mathrm{~L}^{-1}$ fueron los que mantuvieron sus características físicas y químicas normales de maduración, por $5 \mathrm{~d}$ a $25^{\circ} \mathrm{C}$, previo a $20 \mathrm{~d}$ a $13^{\circ} \mathrm{C}$. Se concluyó que la aplicación de 1-MCP a $1000 \mathrm{~nL} \mathrm{~L}^{-1}$ por $24 \mathrm{~h}$ a $20{ }^{\circ} \mathrm{C}$ y posterior almacenamiento de $20 \mathrm{~d}$ a $13^{\circ} \mathrm{C}$ puede ser una ayuda para transportar el mango Ataulfo a mercados lejanos donde no demandan el tratamiento hidrotémico.

Palabras clave: Mango Ataulfo, 1-metilciclopropeno (1-MCP), etileno, maduración.

\section{SUMMARY}

This work evalated the effect of 1-methylcyclopropene (1-MCP) on the ripening process and quality of mangoes (Mangifera indica L.) var. Ataulfo stored for $20 \mathrm{~d}$ at $13{ }^{\circ} \mathrm{C}$ and $5 \mathrm{~d}$ at $25^{\circ} \mathrm{C}$ to simulate shipping and distribution conditions in Europe. This research generated knowledge about the effect of 1-MCP on ethylene metabolism, and provided information on the conditions of application of 1-MCP on this mango variety. Fruits with and without hydrothermal treatment ( $\mathrm{CH}$ and SH, respectively) were treated with 1-MCP $(300,600$, and $1000 \mathrm{~nL} \mathrm{~L}^{-1}$ ). Respiration rate (RR), ethylene production rate (EPR), content of aminocyclopropane-1-carboxylic acid (ACC), ACC oxidase activity, transcript levels (ETR1 and ACO), as well as physical and chemical variables were monitored. The highest RR was 129.12 and $129.37 \mathrm{~mL} \mathrm{CO}_{2} \mathrm{~kg}^{-1} \mathrm{~h}^{-1}$ at days 1 and 4 at $25^{\circ} \mathrm{C}$, respectively for $\mathrm{SH}$ and $\mathrm{CH}$ control fruits; while EPR was 0.15 and 0.23 $\mu \mathrm{Lg}^{-1} \mathrm{~h}^{-1}$. RR decreased in fruits treated with 1-MCP $\left(86.17 \mathrm{~mL} \mathrm{CO}_{2} \mathrm{~kg}^{-1} \mathrm{~h}^{-1}\right)$, as well as EPR $\left(0.13 \mu \mathrm{L} \mathrm{kg}^{-1} \mathrm{~h}^{-1}\right)$, ACC oxidase activity and the expression of ETR1 and $A C O$ genes, after transfer to $25^{\circ} \mathrm{C}$ ( 4 to $5 \mathrm{~d}$ ). In CH fruits treated with 1 -MCP these changes were not observed. SH mangoes treated with $1000 \mathrm{~nL} \mathrm{~L}^{-1}$, maintained physical and chemical characteristics of normal ripening for $5 \mathrm{~d}$ at $25^{\circ} \mathrm{C}$, and after $20 \mathrm{~d}$ at $13^{\circ} \mathrm{C}$. It was concluded that 1-MCP application at 1000 $\mathrm{nL} \mathrm{L}-1$ for $24 \mathrm{~h}$ at $20^{\circ} \mathrm{C}$ and posterior storage during $20 \mathrm{~d}$ at $13^{\circ} \mathrm{C}$ could aid in transportation of Ataulfo mangoes to distant markets where the hydrothermal treatment is not required.

Index words: Mango Ataulfo, 1-methylcyclopropene (1-MCP), ethylene, ripening.

\section{INTRODUCCIÓN}

México es uno de los principales exportadores de mango (Mangifera indica L.) ya que la calidad de los frutos es de excelente aceptabilidad en los mercados de Estados Unidos, Canadá, Japón, Reino Unido y los Países Bajos (SAGARPA, 2014). Sin embargo, la necesidad de explorar nuevos mercados continúa y otros países de Europa tienen un importante potencial como consumidores. Actualmente, el transporte de mango a Europa es por vía marítima con una duración de 18 a $20 \mathrm{~d}$ a $13^{\circ} \mathrm{C}$, condiciones en las que el fruto llega en estado avanzado de madurez y solo deja de 2 a $3 \mathrm{~d}$ para comercializarlo en su mayoría en mercados cercanos al desembarque (Osuna et al., 2007). Por ello se requiere combinar tecnologías que permitan reducir la velocidad de maduración de los frutos y prolongar su vida post-cosecha, para permitir distribuir el mango mexicano al resto de países de Europa.

El 1-metilciclopropeno (1-MCP) es un compuesto químico que actúa como antagonista del etileno y retrasa la maduración de frutas y hortalizas; su efectividad es dependiente del cultivar, temperatura de aplicación, dosis, 
duración del tratamiento y grado de madurez, principalmente. Además, si los frutos son expuestos a tratamientos post-cosecha previos a la aplicación del antagonista, su respuesta puede variar (Blankenship y Dole, 2003). La aplicación de 1-MCP en mangos de las variedades Kent (Osuna-García et al., 2005), Keitt (Osuna-García et al., 2007; Osuna-García et al., 2009) y Tommy Atkins (PereiraBomfim et al., 2011) ha retrasado el proceso de maduración al disminuir la pérdida de firmeza y peso, al retrasar el aumento de sólidos solubles totales y el desarrollo de color en la pulpa de los frutos. Para mango Ataulfo solo existe un reporte donde la aplicación de 1-MCP a 400 y $800 \mathrm{~nL} \mathrm{L-1}$ combinado con una película comestible (PC) retrasó la velocidad de respiración y la actividad de las enzimas poligalacturonasa y carboximetilcelulasa, pero no de la a-galactosidasa, $\beta$-galactosidasa y $\beta$-glucosidasa, y sin haber encontrado diferencias en el tiempo de maduración entre los frutos tratados con 1-MCP y los testigos no tratados (Muy et al., 2009).

Para entender el efecto del 1-MCP en la conservación de frutas, actualmente se realizan investigaciones sobre su relación con la expresión de genes que codifican para las enzimas ACC sintasa, ACC oxidasa y receptores del etileno durante la maduración post-cosecha. El tomate (Solanum lycopersicum L.) var. Micro Tom (Severo et al., 2015), las manzanas (Malus domestica L.) de las vars. Empire, Mclntosh y Cortland (Jung y Watkins, 2014) y el plátano (Musa x paradisiaca L.) cv. Brazil (Zhu et al., 2015) tratados con 1-MCP, exhibieron un retraso en la expresión de genes que intervienen en la biosíntesis de etileno lo que favoreció la vida de anaquel de estos frutos. Sin embargo, se ha reportado una acción menos efectiva de este gas en otros cultivares como el brócoli (Brassica oleracea L.) var. Italica (Ma et al., 2009), la 2 (Prunus salicina Lindl.) cv. Tengan Blue (Khan y Singh, 2009), la manzana Granny Smith (Asif et al., 2009) y el mango Ataulfo (Muy et al., 2009).

Existen reportes escasos sobre el efecto del 1-MCP en la biosíntesis de etileno en frutos de mango, los cuales se enfocan principalmente en el efecto favorable para retrasar la velocidad de respiración, el desarrollo de color y la pérdida de firmeza; tampoco existen publicaciones que reporten efectos negativos ni de su efecto en la biosíntesis del etileno para entender su acción. En relación con lo anterior, el objetivo del presente estudio fue evaluar el efecto de dosis de 1-MCP en mango Ataulfo aplicado a diferentes temperaturas, en diferentes estados de madurez, con y sin tratamiento hidrotérmico, sobre parámetros fisiológicos, fisicoquímicos y transcritos que intervienen en la síntesis de etileno durante su almacenamiento para simular el traslado a Europa.

\section{MATERIALES Y MÉTODOS}

\section{Experimento 1}

Se cosecharon frutos de mango Ataulfo en las huertas del poblado Cinco de Mayo, Municipio de Tepic, Nayarit (Latitud $21^{\circ} 03^{\prime} 33^{\prime \prime} \mathrm{N}$, Longitud: $105^{\circ} 18^{\prime} 33^{\prime \prime} \mathrm{O}$ ), en las temporadas 2013 y 2014. Los frutos cosechados eran de color verde claro con 3/4 de color amarillo, acidez titulable de $4.9 \%$ como ácido cítrico y un contenido de sólidos solubles totales de $5.3^{\circ}$ Brix. Las frutas con tratamiento hidrotérmico se introdujeron en agua a $46.1^{\circ} \mathrm{C}$ por $75 \mathrm{~min}$ y posteriormente en tratamiento de hidroenfriado a $21^{\circ} \mathrm{C}$ por 30 min el mismo día de la cosecha.

Los frutos se dividieron en seis lotes de 50 frutos cada uno, correspondientes a seis tratamientos. Se emplearon dos lotes como testigo: el primero fue mango sin tratamiento hidrotérmico $(\mathrm{SHO})$, y el segundo fue de mango con tratamiento hidrotérmico $(\mathrm{CHO})$, ambos sin 1-MCP. El tercer y cuarto lotes de frutos fueron tratados con 1-MCP a $300 \mathrm{~nL} \mathrm{~L}^{-1}, \sin (\mathrm{SH} 300)$ y con tratamiento hidrotérmico (CH300). A los dos lotes restantes se les aplicó $600 \mathrm{~nL} \mathrm{~L}^{-1}$ de 1-MCP $\sin (\mathrm{SH600)}$ y con tratamiento hidrotérmico (CH600). La aplicación de 1-MCP (SmartFresh ${ }^{\mathrm{TM}}$ Technology, AgroFresh Inc. PA, USA), fue al momento del día de cosecha y se realizó en un cuarto de refrigeración a $13 \pm$ $1^{\circ} \mathrm{C}$.

La exposición al 1-MCP se realizó en cámaras de $225 \mathrm{~L}$ herméticamente selladas, con un ventilador en su interior para homogenizar el tratamiento con 1-MCP por $24 \mathrm{~h}$; después de ese tiempo todos los frutos fueron almacenados en una cámara de refrigeración con recirculación de aire, por 20 d a $13 \pm 1{ }^{\circ} \mathrm{C}$ y de 85 a $90 \%$ de humedad relativa (HR) para simular el traslado a Europa y luego transferidos a $25 \pm 2{ }^{\circ} \mathrm{C}$ (de 85 a $90 \%$ HR) hasta su maduración para simular las condiciones de mercadeo. Se midió cada $2 \mathrm{~d}$ la velocidad de respiración (VR) y velocidad de producción de etileno (VPE) durante la simulación de transporte a Europa y diariamente durante la simulación de mercadeo; las variables firmeza, $\mathrm{pH}$, acidez titulable (AT), sólidos solubles totales (SST) y porcentaje de madurez, se midieron los días 1 y 20 en refrigeración, y 3 d después de su traslado a $25 \pm 2{ }^{\circ} \mathrm{C}$.

\section{Experimento 2}

Con el mejor tratamiento del experimento 1 y sin aplicación del tratamiento hidrotérmico, se muestrearon frutos en una madurez de cosecha determinada que fue: color verde claro (sin presencia de pigmentos amarillos), acidez 
titulable de $5.3 \%$ de ácido cítrico y sólidos solubles totales de $3.9^{\circ}$ Brix. Se analizaron tres lotes de 50 frutos cada uno: a) Frutos tratados con 1-MCP a 600 (SH600); b) Frutos tratados con $1000 \mathrm{~nL} \mathrm{~L}-1$ (SH1000) a $20 \pm 1{ }^{\circ} \mathrm{C}$ por $24 \mathrm{~h}$ y c) Frutos testigo sin 1-MCP (SHO). Los mangos se almacenaron como en el primer experimento.

Para evaluar el efecto del 1-MCP en la biosíntesis de etileno durante el almacenamiento, cada 3 d se midió el contenido del ácido 1-aminociclopropano-1-carboxílico (ACC) y la actividad de la enzima ácido 1-aminociclopropano-1-carboxílico oxidasa (ACC oxidasa, EC 1.14.17.4). Las variables firmeza, $\mathrm{pH}, \mathrm{AT}$, SST y porcentaje de madurez se midieron como se mencionó anteriormente. Así mismo se evaluó la expresión del transcrito de la enzima ACC oxidasa (ACO-7) y un receptor de etileno (Mi-ETR1), de frutos sin (SH0) y con 1-MCP (SH600, SH100), solo cuando los frutos se almacenaron a $25 \pm 2{ }^{\circ} \mathrm{C}$ por $1,3,4$ y $5 \mathrm{~d}$.

\section{Métodos de análisis}

Las variables velocidad de respiración (VR) y velocidad de producción de etileno (VPE) se midieron por el método de Tovar et al. (2001), en frutos individuales que se colocaron en recipientes herméticos por $1 \mathrm{~h}$ para VR y $12 \mathrm{~h}$ para VPE, a estos últimos se les colocó una sustancia absorbente de $\mathrm{CO}_{2}$ (solución saturada con $\mathrm{NaOH}$ marca Analytika), con el objeto de disminuir la concentración de $\mathrm{CO}_{2}$ en el interior del recipiente y no afectar la maduración de los frutos.

Se tomó $1 \mathrm{~mL}$ de gas del espacio de cabeza y se analizó en un cromatógrafo de gases (HP® modelo 6890, USA) con una columna HP-plot $(15 \mathrm{~m} \times 0.53 \mathrm{~mm}$ y $40 \mu \mathrm{m}$ de espesor de película), un detector de ionización de flama (FID) y un detector de conductividad térmica (TCD). La temperatura del puerto de inyección y de los detectores fue de $250^{\circ} \mathrm{C}$. Dentro de este mismo sistema se utilizó $\mathrm{H}_{2}\left(30 \mathrm{~mL} \mathrm{~min}^{-1}\right)$ y aire $\left(400 \mathrm{~mL} \mathrm{~min} \mathrm{~m}^{-1}\right)$. La temperatura del horno fue una rampa de 60 a $80^{\circ} \mathrm{C}$, la cual cambió a una velocidad de $30{ }^{\circ} \mathrm{C} \mathrm{min}^{-1}$. El gas acarreador fue $\mathrm{N}_{2}$ con un

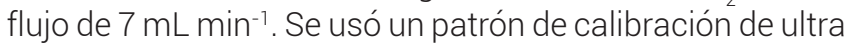
alta pureza (5.0) certificado Praxairß con $11.3 \mu^{m o l ~ m o l^{-1}}$

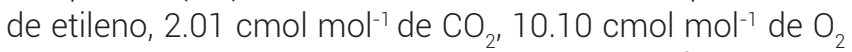
y $\mathrm{N}_{2}$ para balancear la mezcla. La concentración de $\mathrm{CO}_{2}$ y etileno se calculó usando una relación directamente proporcional al área obtenida de los estándares (áreas de un promedio de 10 inyecciones) a la concentración respectiva, con el área de la muestra problema. La VR se expresó en $\mathrm{mLCO} \mathrm{kg}^{-1} \mathrm{~h}^{-1}$ y la VPE en $\mu \mathrm{L} \mathrm{kg}^{-1} \mathrm{~h}^{-1}$.

La actividad de la ACC oxidasa se determinó in vivo, en $0.5 \mathrm{~g}$ de tejido de mango en forma de discos de $1 \mathrm{~mm}$ de espesor y $8 \mathrm{~mm}$ de diámetro, los cuales se incubaron con
$0.7 \mathrm{~mL}$ de ACC $0.1 \mathrm{mM}$ (Sigma) por $4 \mathrm{~h}$ a $25^{\circ} \mathrm{C}$, en un vial con septa y con agitación constante. Después de las $4 \mathrm{~h}$ de incubación, $1 \mathrm{~mL}$ del gas del espacio libre de cabeza del vial se inyectó al cromatógrafo de gases (Cua y Lizada, 1990). Se determinó la cantidad de etileno producida, y se expresó en $\mathrm{nmoL}$ etileno $\mathrm{h}^{-1}$.

El ACC se extrajo de $2 \mathrm{~g}$ de pulpa de mango con etanol ( $80 \% \mathrm{v} / \mathrm{v}$ ), se centrifugó a 12,325 Xg por 30 min en una centrífuga ALC® modelo PM180R (Italia) y el sobrenadante se evaporó para eliminar el etanol. El ACC extraído se recuperó con $2 \mathrm{~mL}$ de agua desionizada y se hizo una purificación previa del extracto haciéndolo pasar a través de $2 \mathrm{~g}$ de resina Dowex 50W-X8, 50-100 mesh, H+ form (Sigma) en agitación por 20 min y se agregaron $5 \mathrm{~mL}$ de $\mathrm{NH}_{4} \mathrm{OH} 0.1 \mathrm{~N}$. Se tomó $1 \mathrm{~mL}$ de la solución y se colocó en un vial de $20 \mathrm{~mL}$ que contenía o no $2.5 \mathrm{nmol}$ de ACC y $1 \mathrm{~mL}$ de $\mathrm{HgCl}_{2} 5 \mathrm{mM}$; después se sellaron los viales y se colocaron en hielo.

Para la conversión de ACC a etileno se agregaron cinco gotas de hipoclorito alcalino ( $\mathrm{NaOCl}$ al $5 \%$ ). La eficiencia de conversión de ACC a etileno en cada muestra fue determinada con la réplica, la cual contenía $2.5 \mathrm{nmol}$ de ACC como estándar interno. La cantidad de ACC en la muestra se calculó como la cantidad de etileno liberada en la muestra dividida por la eficiencia de conversión (Lizada y Yang, 1979) y se reporta en $\mathrm{nmoL} \mathrm{g}^{-1}$ de muestra fresca.

La firmeza de los mangos se determinó con un penetrómetro Shimpo® modelo FGV-50 (Japón) con un puntal cilíndrico de $10 \mathrm{~mm}$ de diámetro. A cada fruto se le hicieron cortes de $1 \mathrm{~cm}$ de grosor a cada lado del mismo, y ahí se efectuaron tres mediciones en las partes apical, central y pedúnculo y los datos se expresaron en newtons (N). Los sólidos solubles totales (SST) se determinaron en pulpa fresca homogeneizada, una porción de la cual se colocó en tela y se exprimió para obtener el jugo y medir los SST en un refractómetro (Atago®, Modelo AD-13, Japón).

La acidez titulable (AT) se determinó por el método volumétrico 942.15 AOAC (2005). Los resultados se expresaron en porcentaje de ácido cítrico. El pH se midió directamente en la pulpa homogeneizada con un potenciómetro (JenCo®, Modelo 1671, Rumania). El color externo se midió con la escala siguiente: 1 = verde, 2 = verde con tonos amarillos, 3 = igual cantidad de verde y amarillo, $4=$ amarillo con tonos verdes, 5 = amarillo, 6 = amarillo con tonos naranjas. Se utilizaron 20 frutos por tratamiento y los resultados se reportan en por ciento de frutos situados en cada uno de los estados de madurez (Montalvo et al., 2007).

La técnica de Northern Blotting se usó para el análisis de transcritos de ACC oxidasa (ACO-7) en frutos de los tratamientos SHO y SH600 en los días 1, 3, 4 y 5 después de 
estar almacenados a $25 \pm 2{ }^{\circ} \mathrm{C}$ y para los frutos $\mathrm{SH} 1000$ sólo a los $5 \mathrm{~d}$ a $25 \pm 2{ }^{\circ} \mathrm{C}$. El análisis del receptor de etileno (Mi-ETR1) se hizo en los días 4 y 5 a $25 \pm 2{ }^{\circ} \mathrm{C}$. La extracción y separación por electroforesis del ARNm fue realizada de acuerdo con la técnica propuesta por López-Gómez y Gómez-Lim (1992). La transferencia de los transcritos del gel de electroforesis a la membrana de nailon se llevó a cabo según Sambrook y Russell (2001).

La sonda de transcritos de la ACC oxidasa se obtuvo del plásmido pKYCPACO-1 en E. coli (López-Gómez et al., 2009). La sonda del transcrito del receptor de etileno de mango (Mi-ETR1) se realizó con el DNA plasmídico de E. coli, la cual contenía el vector pBLUESCRIPT (M13+/ M3-) con resistencia a kanamicina y el fragmento de interés (Gutiérrez et al., 2001). Las sondas purificadas fueron marcadas radioactivamente con el isótopo [a 32 P] dCTP $3000 \mathrm{Ci} / \mathrm{mmol}$. Una vez marcadas las sondas, se procedió a la hibridación de éstas con el ARNm previamente obtenido del mango Ataulfo durante toda la noche a $65^{\circ} \mathrm{C}$ con agitación constante. Las membranas fueron colocadas sobre películas de autorradiografía (Amersham Hyperfilm MP) en oscuridad a $-80^{\circ} \mathrm{C}$ por $24 \mathrm{~h}$. Las películas fueron reveladas en un equipo Kodak $\AA$ modelo X-OMAT 1000A (Rochester, NY, USA).

Para el primer experimento se utilizó un diseño de bloques completos al azar, con arreglo factorial $(2 \times 3)$ para evaluar el tratamiento hidrotérmico (con y sin) y tres concentraciones de 1-MCP $\left(0,300\right.$ y $\left.600 \mathrm{~nL} \mathrm{~L}^{-1}\right)$; los bloques fueron los días de almacenamiento. Para el segundo experimento el diseño también fue en bloques al azar para evaluar tres concentraciones de 1-MCP y el bloqueo también se hizo en función de los días de almacenamiento. Los datos se analizaron estadísticamente mediante un análisis de varianza (ANOVA, por sus siglas en inglés), con comparaciones de medias por la prueba de LSD $(P \leq 0.05)$, con empleo del paquete estadístico SAS (The SAS System for Windows ${ }^{\circledR}$, Version 9.0 Institute, Inc. Cary, NC. 2002).

\section{RESULTADOS Y DISCUSIÓN}

\section{Experimento 1}

\section{Velocidad de respiración y producción de etileno}

Durante los $20 \mathrm{~d}$ de almacenamiento a $13 \pm 1^{\circ} \mathrm{C}$ no se detectó etileno en los frutos $\mathrm{SH}$ y CH (Figuras $1 \mathrm{~A}$ y B), lo que se puede atribuir a la baja actividad metabólica de los mangos por efecto de la temperatura de refrigeración, lo cual coincide con lo reportado por Montalvo et al. (2007) quienes no detectaron etileno en frutos de mango Ataulfo almacenados por $4 \mathrm{~d}$ a $13 \pm 1{ }^{\circ} \mathrm{C}$. Hubo efecto significativo $(P<0.05)$ en la VPE por las concentraciones de 1-MCP aplicadas en los frutos $\mathrm{SH}$. Al día siguiente de transferir los frutos a $25 \pm 2{ }^{\circ} \mathrm{C}\left(20 \mathrm{~d}\right.$ a $13 \pm 1{ }^{\circ} \mathrm{C}+1 \mathrm{~d}$ a $\left.25 \pm 2{ }^{\circ} \mathrm{C}\right)$, se detectó etileno en los frutos SHO $\left(0.038 \mu \mathrm{L} \mathrm{kg}^{-1} \mathrm{~h}^{-1}\right)$ y SH300 $\left(0.036 \mu \mathrm{L} \mathrm{kg}^{-1} \mathrm{~h}^{-1}\right)$ sin diferencias significativas $(P>0.05)$ entre estos dos tratamientos (Figura 1A). En los frutos de SH600 la detección de VPE fue 1 d después, siendo estadísticamente diferente $(P<0.05)$ y con menor producción de esta fitohormona $\left(0.022 \mu \mathrm{L} \mathrm{kg}^{-1} \mathrm{~h}^{-1}\right)$ que los frutos de $\mathrm{SHO}$ y SH300. Esto significa que el 1-MCP a $600 \mathrm{~nL} \mathrm{~L}^{-1}$ redujo la VPE en estos frutos debido a la disminución en la actividad de las enzimas reguladoras de la biosíntesis del etileno o de la expresión genética de las mismas (Villalobos-Acuna et al., 2011; Yang et al., 2013).

Respecto a los frutos $\mathrm{CH}$, una vez que los frutos fueron trasladados a $25 \pm 2{ }^{\circ} \mathrm{C}$ (Figura 1B), la producción de etileno aumentó significativamente durante su maduración, y al final del almacenamiento (día 5 a $25 \pm 2{ }^{\circ} \mathrm{C}$ ) la VPE fue de 0.54 a $0.59 \mu \mathrm{L} \mathrm{kg}^{-1} \mathrm{~h}^{-1}$, sin diferencias significativas $(P>$ $0.05)$ entre tratamientos. Datos parecidos reportó Zóffoli (2000) para duraznos (Prunus persica L.) y nectarinas (Prunus persica var. Nucipersica), quien no encontró efecto del 1-MCP sobre la producción de etileno en los frutos con tratamiento hidrotérmico y discute que el uso de agua caliente previo a la aplicación de 1-MCP acelera el metabolismo de los frutos; este mismo comportamiento se observa aquí en los mangos $\mathrm{CH}$ (Figura 1B). Recientemente se encontró que el tratamiento hidrotérmico $\left(48{ }^{\circ} \mathrm{C}, 10 \mathrm{~min}\right)$ y la aplicación de 1-MCP en durazno, por un lado inducen la expresión de algunos genes de la maduración, pero se inhiben otros, lo que indica la complejidad intrínseca en el control de la maduración (Jiang et al., 2014).

La velocidad de respiración (VR) se mantuvo baja durante el almacenamiento a $13 \pm 1{ }^{\circ} \mathrm{C}$ independientemente de que los frutos fueran $\mathrm{CH}$ y SH, tratados o no con 1-MCP (Figuras $1 C$ y D). Aunque, se observa que durante el almacenamiento por 3,6 y $9 \mathrm{da} 13 \pm 1^{\circ} \mathrm{C}$, la VR (de 7.75 a 10.58 $\mathrm{mL} \mathrm{CO} \mathrm{kg}^{-1} \mathrm{~h}^{-1}$ ) en los frutos $\mathrm{SH} 600$ fue significativamente menor ( $\mathrm{P} \leq 0.05)$ que en los frutos SHO y SH300 (de 18.64 a 26.88 y de 14.90 a $27.06 \mathrm{~mL} \mathrm{CO}_{2} \mathrm{~kg}^{-1} \mathrm{~h}^{-1}$, respectivamente).

Los frutos $\mathrm{CHO}$ presentaron una VR más alta (67.92 $\mathrm{mL} \mathrm{CO} \mathrm{kg}^{-1} \mathrm{~h}^{-1}$ ) a los $18 \mathrm{~d}$ en comparación con los otros tratamientos, es posible que en este periodo de almacenamiento el 1-MCP y la temperatura estuvieran ejerciendo una disminución en la VR. Una vez transferidos a 25 $\pm 2{ }^{\circ} \mathrm{C}$, la VR aumentó en todos los frutos hasta llegar a $129.12 \mathrm{~mL} \mathrm{CO}_{2} \mathrm{~kg}^{-1} \mathrm{~h}^{-1}$ para frutos $\mathrm{SHO}$, a $87.83 \mathrm{~mL} \mathrm{CO}_{2}$ $\mathrm{kg}^{-1} \mathrm{~h}^{-1}$ para frutos SH300 y a $86.71 \mathrm{~mL} \mathrm{CO}_{2} \mathrm{~kg}^{-1} \mathrm{~h}^{-1}$ para frutos SH600 a los $4 \mathrm{~d}$ a $25 \pm 2{ }^{\circ} \mathrm{C}$ (máximo climaterio), con diferencias significativas $(P<0.05)$. En cambio, para los frutos $\mathrm{CHO}, \mathrm{CH} 300$ y $\mathrm{CH} 600$ la máxima VR fue de $129.37,129.56$ y $119.86 \mathrm{~mL} \mathrm{CO}_{2} \mathrm{~kg}^{-1} \mathrm{~h}^{-1}$ respectivamente, 
$1 \mathrm{~d}$ después del traslado a $25 \pm 2{ }^{\circ} \mathrm{C}$ y sin diferencias significativas entre tratamientos $(P>0.05)$.

El rápido aumento de la VR al cambiar de temperatura de almacenamiento evidencia el efecto de temperatura en la VR debido al aumento en la actividad metabólica, efecto que ya se ha reportado en mango Keitt (Osuna et al., 2007). El efecto del 1-MCP en la VR sólo se observó en los frutos $\mathrm{SH}$. Estos resultados coinciden con el efecto del 1-MCP observado en la VPE; así como en lo reportado por Li et al. (2013), quienes observaron que el tratamiento de $500 \mathrm{~nL}$ $\mathrm{L}^{-1}$ de 1 -MCP por $18 \mathrm{~h}$ a $20^{\circ} \mathrm{C}$ en pera (Pyrus bretschneideri Reld cv. Laiyang), disminuyó la VR durante los primeros días de almacenamiento y retrasó la aparición del pico climatérico, debido a la disminución en la actividad de las enzimas que intervienen en la respiración.
El efecto significativo $(P<0.05)$ del tratamiento hidrotérmico en la VR también fue evidente, ya que hubo una mayor velocidad de producción de $\mathrm{CO}_{2}$ independientemente del tratamiento con 1-MCP, en comparación con los frutos SH. Los resultados son similares a los que reporta Osuna et al. (2007), estos autores no encontraron diferencias en la VR del mango Keitt $\mathrm{CH}$, tratado con 1-MCP, y explicaron que el tratamiento hidrotérmico acelera la actividad enzimática del metabolismo respiratorio y la producción de etileno; por ende, al aplicar el 1-MCP su efectividad se ve disminuida y ello repercute en un aumento en la VR.

El efecto estadístico principal $(P<0.05)$ del 1 -MCP en la VPE y VR, estuvo en función de la concentración y del tratamiento hidrotérmico. A mayor concentración de 1-MCP usada y sin tratamiento hidrotérmico, se retrasó la
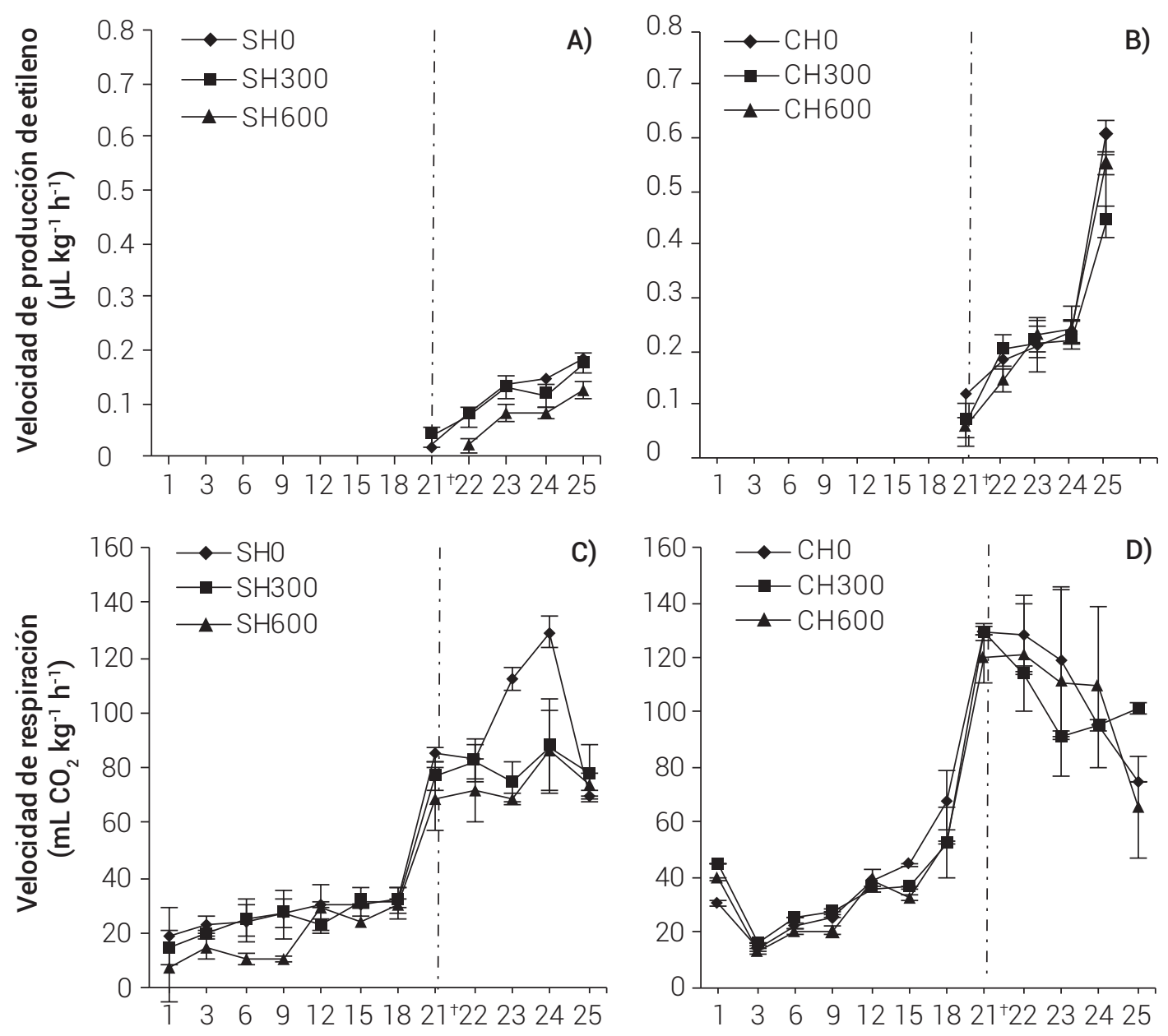

Días de almacenamiento

Figura 1. Velocidad de respiración y velocidad de producción de etileno en mango de la var. Ataulfo sin (SH) y con (CH) tratamiento hidrotérmico, tratado con 0 (SH0, $\mathrm{CH} 0), 300(\mathrm{SH} 300, \mathrm{CH} 300)$ y $600\left(\mathrm{SH} 600, \mathrm{CH}_{600}\right) \mathrm{nL} \mathrm{L}^{-1}$ de $1-\mathrm{MCP}$ por $24 \mathrm{~h}$ a $13 \pm 1^{\circ} \mathrm{C}$, almacenado por $20 \mathrm{~d}$ a $13 \pm 1^{\circ} \mathrm{C}$ y después a $25 \pm 2{ }^{\circ} \mathrm{C}\left({ }^{+}\right)$. 
respiración y producción de etileno; pero no tiene efecto este antagonista si los frutos son tratados con hidrotérmico indicando que la tecnología es viable sólo para frutos $\mathrm{SH}$. Respecto al factor tratamiento hidrotérmico, este fue significativo $(P<0.05)$ por sí mismo, ya que la VPE y VR fueron más altas en los frutos $\mathrm{CH}$, independientemente de la concentración de 1-MCP aplicada, lo que indica que este tratamiento afecta la eficiencia del 1-MCP y no es recomendable aplicarse en esta variedad si se desea trasladar a Europa. La interacción entre factores no fue significativa $(P>0.05)$.

\section{Características fisicoquímicas}

El tratamiento hidrotérmico y el 1-MCP influyeron estadísticamente $(P<0.05)$ en la firmeza del mango Ataulfo (Cuadro 1). Cuando la firmeza fue medida a los $20 \mathrm{~d}$ a 13 $\pm 1{ }^{\circ} \mathrm{C}$, se pudo constatar que la firmeza había disminuido de 125.2 o $130.4 \mathrm{~N}$ hasta $41 \mathrm{~N}$ para los frutos $\mathrm{SHO}$, a 45.9 $\mathrm{N}$ para los frutos de $\mathrm{SH} 300$ y a $47.7 \mathrm{~N}$ para los frutos de SH600; por tanto, el 1-MCP a la dosis de $600 \mathrm{~nL} \mathrm{~L}^{-1}$ tuvo efecto significativo $(P<0.05)$ en la firmeza de estos frutos. Se ha reportado que la retención de firmeza en mango Ataulfo tratado con 1-MCP, se debe a que este gas disminuye la actividad de las enzimas poligalacturonasa y carboximetilcelulasa (Muy et al., 2009).

Posteriormente cuando los frutos se trasladaron a $25 \pm$ $2{ }^{\circ} \mathrm{C}$ y pasaron $3 \mathrm{~d}$ de su almacenamiento, la firmeza fue estadísticamente igual $(P>0.05)$ en los frutos $\mathrm{SHO}$ y SH300, aunque los frutos SH600 tuvieron una firmeza ligeramente mayor. Es probable que a $25 \pm 2{ }^{\circ} \mathrm{C}$ con el aumento de la actividad metabólica por efecto de la temperatura y mayor velocidad de producción de etileno (VPE) (Figura 1A), la pérdida de firmeza se haya acelerado en frutos de SHO y $\mathrm{SH} 300$, ya que se ha demostrado que el etileno regula la actividad de las enzimas que degradan la pared celular (Ketsa et al., 1998).

En los frutos $\mathrm{CH}$ la firmeza disminuyó de 127 o $130.4 \mathrm{~N}$ a $40.0 \circ 40.2 \mathrm{~N}$ a los $20 \mathrm{~d}$ de almacenamiento a $13 \pm 1^{\circ} \mathrm{C}$. Hubo una pérdida de firmeza estadísticamente $(P<0.05)$

Cuadro 1. Características fisicoquímicas en mango var. Ataulfo $\sin (\mathrm{SH})$ y con $(\mathrm{CH})$ tratamiento hidrotérmico, tratado sin $0(\mathrm{SHO}, \mathrm{CHO})$ y con $300(\mathrm{SH} 300, \mathrm{CH} 300)$ o $600(\mathrm{SH} 600, \mathrm{CH} 600) \mathrm{nL} \mathrm{L}-1$ de $1-\mathrm{MCP}$ por $24 \mathrm{~h} \mathrm{a} 13 \pm 1^{\circ} \mathrm{C}$, luego almacenado por $20 \mathrm{~d}$ a $13 \pm 1{ }^{\circ} \mathrm{C}$, y después a $25 \pm 2{ }^{\circ} \mathrm{C}$.

\begin{tabular}{|c|c|c|c|c|c|c|}
\hline \multirow{2}{*}{$\begin{array}{l}\text { Días de } \\
\text { almacenamiento }\end{array}$} & \multicolumn{6}{|c|}{ Experimento 1} \\
\hline & $\mathrm{SHO}$ & $\mathrm{SH} 300$ & SH600 & $\mathrm{CHO}$ & $\mathrm{CH} 300$ & $\mathrm{CH} 600$ \\
\hline & \multicolumn{6}{|c|}{ Firmeza $(\mathrm{N})$} \\
\hline $1^{\dagger}$ & $125.2 \pm 1.3 a$ & $130.4 \pm 1.2 \mathrm{a}$ & $128.5 \pm 1.2 \mathrm{a}$ & $130.0 \pm 1.8 \mathrm{a}$ & $127.3 \pm 1.8 a$ & $130.4 \pm 1.2 \mathrm{a}$ \\
\hline $20^{+}$ & $41.0 \pm 3.9 b$ & $45.9 \pm 1.1 b$ & $47.7 \pm 4.6 \mathrm{a}$ & $40.0 \pm 6.7 c$ & $40.2 \pm 1.4 \mathrm{C}$ & $40.4 \pm 1.6 c$ \\
\hline \multirow[t]{2}{*}{$3^{+1}$} & $13.4 \pm 1.3 b$ & $14.2 \pm 1.4 \mathrm{ab}$ & $15.1 \pm 1.2 \mathrm{a}$ & $12.6 \pm 1.6 b$ & $13.4 \pm 1.2 b$ & $14.2 \pm 1.1 \mathrm{ab}$ \\
\hline & \multicolumn{6}{|c|}{$\mathrm{pH}$} \\
\hline $1^{\dagger}$ & $2.9 \pm 0.1 \mathrm{a}$ & $2.8 \pm 0.1 \mathrm{a}$ & $2.9 \pm 0.1 \mathrm{a}$ & $2.9 \pm 0.1 \mathrm{a}$ & $2.7 \pm 0.1 \mathrm{a}$ & $2.9 \pm 0.1 \mathrm{a}$ \\
\hline $20^{+}$ & $3.8 \pm 0.1 \mathrm{a}$ & $3.7 \pm 0.1 \mathrm{a}$ & $3.0 \pm 0.4 \mathrm{ab}$ & $3.8 \pm 0.1 \mathrm{a}$ & $3.7 \pm 0.2 \mathrm{a}$ & $3.5 \pm 0.2 \mathrm{ab}$ \\
\hline \multirow[t]{2}{*}{$3^{+t}$} & $4.4 \pm 0.1 \mathrm{a}$ & $4.4 \pm 0.1 \mathrm{a}$ & $4.3 \pm 0.2 \mathrm{a}$ & $4.3 \pm 0.2 \mathrm{a}$ & $4.4 \pm 0.1 \mathrm{a}$ & $4.4 \pm 0.1 \mathrm{a}$ \\
\hline & \multicolumn{6}{|c|}{ Acidez titulable (\% ácido cítrico) } \\
\hline $1^{\dagger}$ & $4.9 \pm 0.1 \mathrm{a}$ & $4.8 \pm 0.0 \mathrm{a}$ & $4.9 \pm 0.0 \mathrm{a}$ & $4.9 \pm 0.1 \mathrm{a}$ & $4.6 \pm 0.1 \mathrm{a}$ & $4.9 \pm 0.1 \mathrm{a}$ \\
\hline $20^{+}$ & $2.7 \pm 0.1 \mathrm{c}$ & $2.8 \pm 0.1 b$ & $3.4 \pm 0.3 a$ & $2.6 \pm 0.4 c$ & $2.5 \pm 0.8 c$ & $2.7 \pm 0.4 \mathrm{bc}$ \\
\hline \multirow[t]{2}{*}{$3^{+t}$} & $0.3 \pm 0.2 \mathrm{ab}$ & $0.4 \pm 0.2 b$ & $0.5 \pm 0.1 \mathrm{ab}$ & $0.3 \pm 0.1 b$ & $0.3 \pm 0.1 b$ & $0.3 \pm 0.2 b$ \\
\hline & \multicolumn{6}{|c|}{ Sólidos solubles totales ( $\left.{ }^{\circ} \mathrm{Brix}\right)$} \\
\hline $1^{+}$ & $5.1 \pm 0.3 \mathrm{a}$ & $5.0 \pm 0.2 \mathrm{a}$ & $5.6 \pm 0.5 a$ & $5.3 \pm 0.10 a$ & $5.1 \pm 0.10 \mathrm{a}$ & $4.9 \pm 0.12 a$ \\
\hline $20^{+}$ & $15.8 \pm 0.1 \mathrm{a}$ & $15.1 \pm 0.4 \mathrm{a}$ & $14.3 \pm 0.4 b$ & $13.3 \pm 2.1 \mathrm{c}$ & $13.0 \pm 3.2 \mathrm{c}$ & $13.6 \pm 1.6 \mathrm{c}$ \\
\hline $3^{+t}$ & $17.1 \pm 0.1 \mathrm{a}$ & $16.0 \pm 0.2 \mathrm{a}$ & $15.2 \pm 0.5 a b$ & $15.0 \pm 0.3 b$ & $15.5 \pm 0.2 a b$ & $15.8 \pm 0.2 \mathrm{a}$ \\
\hline
\end{tabular}

Medias con diferente letra $(\mathrm{a}, \mathrm{b}, \mathrm{c})$ por fila son estadísticamente diferentes $(\mathrm{P} \leq 0.05) .{ }^{\dagger}$ Mango almacenado a $13 \pm 1^{\circ} \mathrm{C}$ por $20 \mathrm{~d} .{ }^{\dagger+} \mathrm{Mango}$ almacenado a $25 \pm 2{ }^{\circ} \mathrm{C}$, previo a $20 \mathrm{~d} \mathrm{a} 13 \pm 2{ }^{\circ} \mathrm{C}$. 
mayor que en los frutos SH, alcanzando valores de 12.6 o $14.2 \mathrm{~N}$ cuando se almacenaron a $25 \pm 2{ }^{\circ} \mathrm{C}(3 \mathrm{~d})$, sin diferencia significativa $(P \geq 0.05)$ entre todos tratamientos $\mathrm{CH}$. Esto se atribuye a que en estos frutos la VPE fue mayor (Figura 1B) y, como se ha indicado en otros trabajos, la actividad de las enzimas que degradan la pared celular son dependientes de la producción de etileno (Ketsa et al., 1998). Los resultados coinciden con lo reportado por Osuna et al. (2007) donde en mango Keitt tratado con $\mathrm{CH}$ (46 ${ }^{\circ} \mathrm{C}$ por $110 \mathrm{~min}$ ) y $1-\mathrm{MCP}\left(300 \mathrm{~nL} \mathrm{~L}^{-1}\right)$ no se observó efecto del 1-MCP en la retención de firmeza.

El efecto principal $(P<0.05)$ encontrado en la firmeza de los factores evaluados fue muy importante, ya que se pudo comprobar que el 1-MCP a $600 \mathrm{~nL} \mathrm{~L}^{-1}$ mantiene los frutos ligeramente más firmes, pero sólo si los frutos no son tratados hidrotérmicamente. Si el mango Ataulfo se trata con hidrotérmico, la pérdida de firmeza se acelera aun cuando los frutos tengan 1-MCP; por tanto el hidrotérmico afecta de manera importante la efectividad del 1-MCP en la firmeza de los frutos.

La acidez titulable (AT) disminuyó y el pH aumentó durante el almacenamiento en refrigeración de los frutos (Cuadro 1). Este cambio en la AT y pH se debe a que en los frutos en estado verde, el contenido de ácidos orgánicos es mayor; sin embargo, a medida que maduran, los ácidos orgánicos disminuyen ya que son sustratos importantes en el metabolismo respiratorio (Tsouvaltziz et al., 2007). En consecuencia, la AT disminuye y el pH aumenta. Al inicio del almacenamiento (día 1) los valores de la AT fueron de 4.6 a $4.9 \%$ (día 1) con un pH de 2.7 a 2.9 en todos los frutos; este valor disminuyó a los $20 \mathrm{~d}$ a $13 \pm 1^{\circ} \mathrm{C}$ hasta $2.5 \mathrm{a}$ $2.8 \%$, con pH de 3.5 a 3.7 para los frutos $\mathrm{SHO}, \mathrm{SH} 300, \mathrm{CHO}$, $\mathrm{CH} 300$ y $\mathrm{CH} 600$, sin diferencias significativas $(P>0.05)$ entre tratamientos. Para los frutos SH600 la disminución de la AT fue $3.4 \%$ con un pH de 3.0, lo cual se atribuye a que el 1-MCP logró reducir la VR de estos frutos (Figura 1C), proceso fisiológico inversamente relacionado con el contenido de ácidos orgánicos (Tsouvaltziz et al., 2007).

Después del traslado a $25 \pm 2{ }^{\circ} \mathrm{C}$, la AT fue de 0.3 a $0.5 \%$ y los valores de $\mathrm{pH}$ fueron de 4.3 a 4.4 sin diferencias significativas $(P>0.05)$ entre tratamientos. Según lo reportado por Amornputti et al. (2014), el 1-MCP no muestra un efecto importante en variables tales como la AT, pH y sólidos solubles totales (SST); estos autores encontraron en frutas durian (Durio zibethinus) cv. Monthong un efecto ligero del 1-MCP sobre los SST, AT y firmeza, y los relacionaron con una disminución de la respiración. Por su parte Osuna et al. (2007) mencionan que el tratamiento hidrotérmico disminuye en mayor proporción la AT, lo que coincide con lo encontrado en este trabajo.
LOS SST aumentaron en los todos frutos evaluados (Cuadro1). Los valores iniciales (día 1) de SST fueron de 4.9 a $5.6^{\circ}$ Brix y al término de este almacenamiento (20 d a $13 \pm 1^{\circ} \mathrm{C}$ ), los SST fueron de 15.1, 15.8 y $14.3^{\circ}$ Brix para frutos de $\mathrm{SHO}, \mathrm{SH} 300$ y SH600, respectivamente. Para los frutos $\mathrm{CH}$ en el mismo periodo a $13 \pm 1{ }^{\circ} \mathrm{C}$, los SST fueron de 13.0 a $13.6^{\circ} \mathrm{Brix}$, sin diferencias significativas $(P>0.05)$ entre todos los tratamientos.

Cuando los frutos se trasladaron a $25 \pm 2{ }^{\circ} \mathrm{C}$ y alcanzaron la madurez de consumo, los SST para los frutos SHO fueron de $17.1^{\circ}$ Brix, de $16.0^{\circ}$ Brix para los frutos de SH30O y de 15.0 a $15.8^{\circ}$ Brix en los frutos de $\mathrm{SH} 600, \mathrm{CHO}, \mathrm{CH} 300$ y $\mathrm{CH} 600$. Se observó un retraso en el aumento de los SST en los frutos SH600. Según Blankenship y Dole (2003), el 1-MCP puede retrasar los cambios en los SST al disminuir el metabolismo respiratorio y ablandamiento de los frutos.

El análisis factorial arrojó que en la acidez titulable, sólo el tratamiento hidrotérmico presentó efecto significativo $(P<0.05)$, siendo menos ácidos los frutos cuando se tratan hidrotérmicamente; esto es congruente con la mayor producción de $\mathrm{CO}_{2}$ en los frutos $\mathrm{CH}$. En el $\mathrm{pH}$ y SST no se encontró efecto $(P>0.05)$ de ninguno de los factores principales evaluados. En general, las características fisicoquímicas se mantienen con valores aceptables cuando los frutos son sometidos a hidrotérmico y 1-MCP, condiciones benéficas que aseguran que los frutos mantienen su calidad cuando maduran.

El desarrollo del color característico de la madurez de los frutos SHO y SH300 fue $100 \%$ con tonalidades amarillo intenso después de $20 \mathrm{~d}$ a $13 \pm 1{ }^{\circ} \mathrm{C}+3 \mathrm{~d}$ a $25 \pm 2{ }^{\circ} \mathrm{C}$ de almacenamiento, con signos de senescencia (pérdida de agua, marchitamiento); los frutos de SH600 mostraron 75 $\%$ de frutos amarillos y $25 \%$ de frutos amarillos con tonalidades verdes en el mismo muestreo, lo que destaca la efectividad significativa $(P<0.05)$ de la dosis del $1-\mathrm{MCP}$ para retrasar la madurez del fruto expresado en el color (degradación de la clorofila y el desarrollo de carotenoides en la cáscara), pero solo si los frutos son SH. Similares resultados obtuvieron Amornputti et al. (2014) en fruta durian $\mathrm{cv}$. Monthong.

En los frutos $\mathrm{CH}$ también se observó que 1-MCP retrasó el desarrollo de tonalidades amarillas durante el almacenamiento a $13 \pm 2{ }^{\circ} \mathrm{C}$, pero después de $2 \mathrm{~d}$ de haber sido transferidos a $25 \pm 2{ }^{\circ} \mathrm{C}$ todos los frutos desarrollaron 100 $\%$ de color amarillo sin diferencias estadísticas significativas $(P>0.05)$. Los resultados coinciden con lo encontrado por Osuna et al. (2007) en mango Keitt con y sin tratamiento hidrótermico y tratados con 1-MCP, en los que reportaron frutos $\mathrm{SH}$ que mostraron un efecto antagonista del etileno 
en el color de la pulpa, pero no así para los frutos $\mathrm{CH}$. Esto debido a una acelerada síntesis de carotenoides inducida por el tratamiento hidrotérmico, antes de la aplicación de 1-MCP en los frutos. Sólo los frutos de mango Ataulfo SH pueden tener 1 o $2 \mathrm{~d}$ más en mercadeo después de su almacenamiento de traslado a Europa.

\section{Experimento 2}

\section{Contenido de ACC y actividad de la ACC oxidasa}

Hasta el día 8 de almacenamiento en refrigeración ( $F i-$ gura 2), el contenido de ACC se mantuvo por debajo de los $20 \mathrm{nmoL} \mathrm{g}{ }^{-1}$ en todos los tratamientos, lo que se atribuye a la baja actividad de la enzima ACC sintasa por efecto de la baja temperatura (Montalvo et al., 2007), acompañado de una reducida biosíntesis de etileno y un lento proceso de maduración. Hubo efecto significativo $(P<0.05)$ de la concentración de 1-MCP. Los frutos SHO (Figura 2A) tuvieron el menor contenido de ACC con un valor máximo de $19.67 \mathrm{nmol} \mathrm{ACC} \mathrm{g}^{-1}$; sin embargo, a mayor dosis de 1-MCP se observó mayor síntesis de ACC con valores máximos de 35.85 y 49.04 nmoL ACC g-1 a los $18 \mathrm{~d}$ para los frutos SH600 y SH1000, respectivamente, y después un descenso (Figura 2B y C).

El mayor aumento del ACC en los frutos tratados con 1-MCP se atribuye a que el antagonista no disminuyó la actividad de la enzima ACC sintasa, pero sí redujo la actividad de la ACC oxidasa, lo que causó una mayor acumulación de ACC en estos frutos. Este resultado coincide con lo reportado por otros autores en manzana y pera respectivamente, que mencionaron que el 1-MCP no disminuye la expresión de algunos genes que codifican para la ACC sintasa (ACS3), al provocar una actividad normal de la enzima (Xie et al., 2014; Yang et al., 2013).

La disminución rápida del ACC en los frutos tratados con 1-MCP no coincidió con el aumento de la VPE para los mismos días. Ello se atribuye a que existen rutas alternas de degradación de ACC (ruta de la malonización) para producir ácido 1-(malonilamino) ciclopropano-1-carboxilico (MACC) en la biosíntesis de etileno, el cual se lleva acabo cuando el fruto se encuentra en estrés (cambio de temperatura de almacenamiento) y está asociado con el aumento de los niveles de ACC (Abeles et al., 1992). La disminución en el contenido de ACC en todos los tratamientos coincidió con el inicio de la actividad de la ACC oxidasa, y se observó que en los frutos en los que se aplicó la mayor concentración de 1-MCP se retrasó la actividad de la enzima; un comportamiento similar se reportó en brócoli (Ma et al., 2009) y ciruela (Khan y Singh, 2009).
El efecto estadístico principal del 1-MCP, arrojó que se llevó acabo la disminución en los compuestos involucrados en la biosíntesis de etileno (ACC y ACC oxidasa) para los frutos $\mathrm{SH} 1000$, y estuvo relacionado con el retraso en la evolución de las variables físicas y químicas medidas. Aunque, se observó un comportamiento similar en la firmeza, AT, pH y SST de los frutos respecto al experimento 1 , el retraso de la maduración fue mayor en los frutos tratados con SH1000. Las pérdidas de firmeza y en AT disminuyeron más lentamente, y el pH y SST ascendieron de manera más lenta, en comparación con los frutos SHO y SH600 (Cuadro 2). Esto coincidió con el porcentaje de frutos maduros, ya que $100 \%$ de frutos SHO y SH6OO se tornaron color amarillo a los 3 d después de trasladarse a $25^{\circ} \mathrm{C}$ con signos de senescencia (reducción de tamaño, marchitamiento); mientras que los frutos SH1000 maduraron $100 \%$ sin signos de senescencia hasta los $27 \mathrm{~d}$, lo que significa un aumento de $5 \mathrm{~d}$ de vida útil en comparación con los otros frutos, al considerar al color como variable de respuesta.

\section{Análisis de transcritos Mi-ETR y ACO-1}

El análisis de los transcritos de la ACC oxidasa (ACO-7) en frutos $\mathrm{SHO}$ y $\mathrm{SH} 600$ almacenados a $25 \pm 2{ }^{\circ} \mathrm{C}$ muestra que la expresión de estos transcritos aumenta durante el tiempo de almacenamiento, pero se puede observar una menor expresión (mancha tenue) en los frutos SH600 a los días 1 y 3 de almacenamiento; sin embargo, a los 5 d no se observa diferencia en expresión entre frutos SH0, SH600 y SH1000 (Figura 3). De la misma manera, desde el día 4 de almacenamiento se observó la expresión del transcrito Mi-ETR1 (Figura 4) tanto en los frutos SHO como en los frutos SH600, aunque la intensidad de expresión fue ligeramente menor en SH600, lo que coincide con la expresión del transcrito ACO-7. En el día 5 de almacenamiento los frutos control ( $\mathrm{SHO}$ ) tuvieron una expresión considerable del transcrito Mi-ETR7 con respecto a los frutos de SH600 y SH1000, lo cual indica que hubo efecto del 1-MCP en el retraso de transcripción de este gen en los frutos tratados.

Los estudios realizados en pera y manzana tratadas con 1-MCP sobre la expresión de los genes de ACC sintasa, ACC oxidasa y receptores de etileno, mostraron que el 1-MCP retardó el proceso de maduración por disminución y retraso de la expresión de los genes ACS1, ACO1 y ACO2, correspondientes de las enzimas evaluadas; así como la reducción en la expresión de genes receptores de etileno a nivel transcripcional (ETR1, ETR2, ETR5, ERSS, CTR1, ElN2A, EIL4 y ERFS).

Sin embargo, no hubo efecto del 1-MCP en la inhibición o retraso de la expresión de los genes ACS3, ACO3, y EIN2B, 
A)

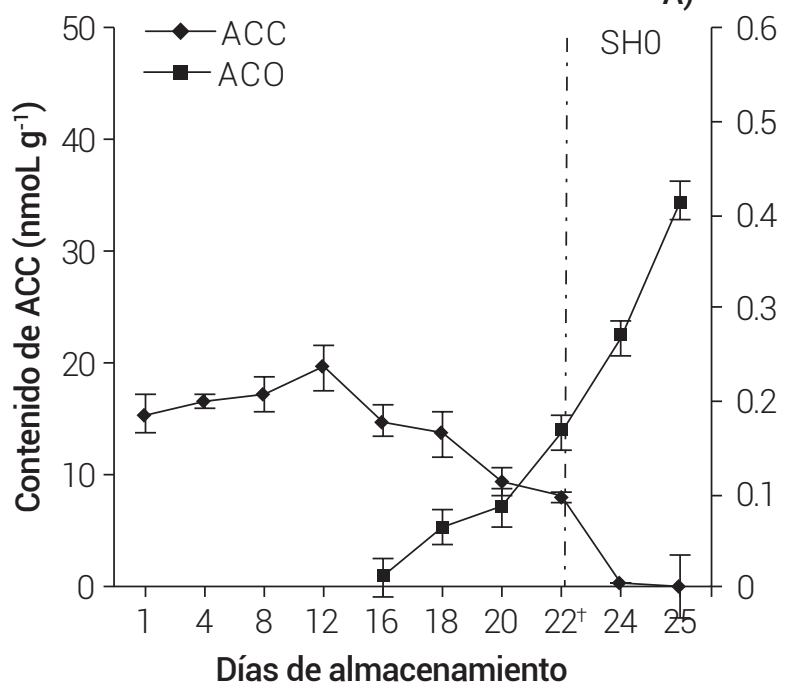

B)

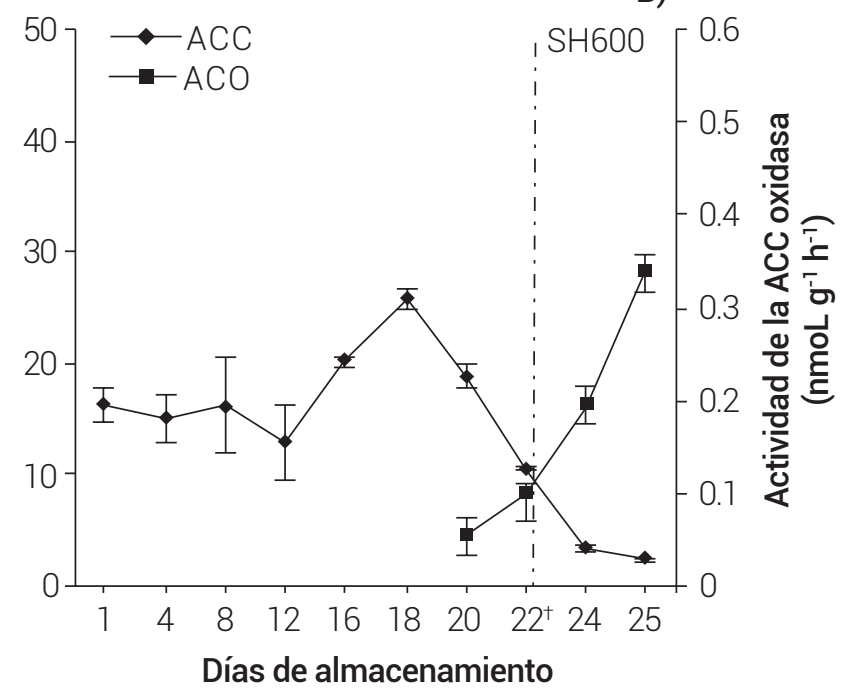

C)

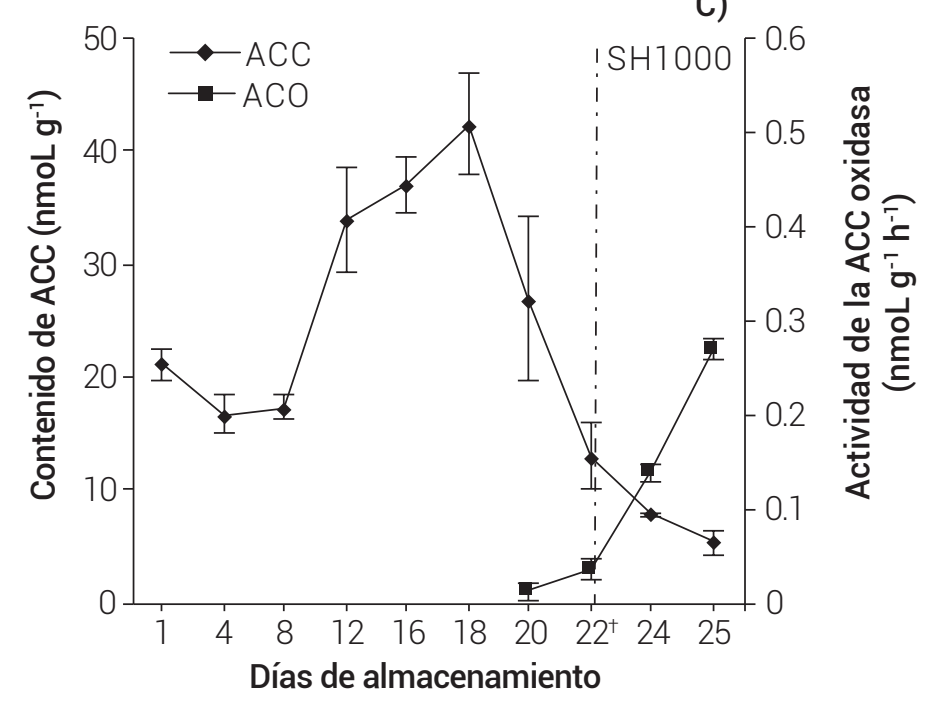

Figura 2. Contenido de ACC y actividad de la ACC oxidasa (ACO) en mango de la var. Ataulfo sin (SH) hidrotérmico, tratado con 0 (SH0), $600(\mathrm{SH} 600)$ y $1000(\mathrm{SH} 1000) \mathrm{nL} \mathrm{L}^{-1}$ de $1-\mathrm{MCP}$ por $24 \mathrm{~h}$ a $20 \pm 1{ }^{\circ} \mathrm{C}$, almacenado por $20 \mathrm{~d}$ a $13 \pm 1^{\circ} \mathrm{C}$ y después a $25 \pm 2{ }^{\circ} \mathrm{C}\left({ }^{+}\right)$.

por lo que los autores concluyeron que si bien algunos genes se reprimen por el 1-MCP, otros pueden iniciar rutas metabólicas alternas de síntesis de etileno (Xie et al., 2014; Yang et al., 2013). Esto quiere decir que la expresión de algunos genes clave para retrasar la maduración de los frutos es variable y dependiente del fruto, lo que explica la inconstante efectividad del 1-MCP entre frutos y hortalizas (Xie et al., 2014).

En este segundo experimento y de acuerdo con el efecto principal encontrado por el 1-MCP, al aumentar la concentración de 1-MCP a frutos SH, la biosíntesis de etileno se retrasa en mayor proporción que en el experimento 1, debido a que hay un retraso en la expresión de transcritos invo- lucrados en la síntesis etileno, hormona de la maduración; estos resultados permiten explicar el aumento adicional en la vida de anaquel de estos frutos.

\section{CONCLUSIONES}

La dosis de $1000 \mathrm{~nL} 1-\mathrm{MCP} \mathrm{L}^{-1}$ sin tratamiento hidrotérmico logró retrasar el proceso de maduración $5 \mathrm{~d}$ en las mismas condiciones de simulación de traslado a Europa, al disminuir la actividad de la ACC oxidasa, expresión de transcritos de ACC oxidasa y receptor de etileno involucrados en la biosíntesis del etileno y la maduración de los frutos. Estos resultados contribuyen a facilitar el mercado de exportación del mango a Europa. 
Cuadro 2. Características fisicoquímicas en mango var. Ataulfo $\sin (\mathrm{SH})$ tratamiento hidrotérmico tratados con 1-MCP por $24 \mathrm{~h}$ a $20^{\circ} \mathrm{C}$ a $0(\mathrm{SH} 0), 600(\mathrm{SH} 600)$ y $1000(\mathrm{SH} 1000) \mathrm{nL} \mathrm{L}^{-1}$, y posteriormente almacenado por $20 \mathrm{~d}$ a $13 \pm 1{ }^{\circ} \mathrm{C}$ y después a $25 \pm 2{ }^{\circ} \mathrm{C}$.

\begin{tabular}{|c|c|c|c|}
\hline \multirow{2}{*}{ Días de almacenamiento } & \multicolumn{3}{|c|}{ Experimento 2} \\
\hline & $\mathrm{SHO}$ & SH600 & SH1000 \\
\hline & \multicolumn{3}{|c|}{ Firmeza $(\mathrm{N})$} \\
\hline $1^{+}$ & $136.5 \pm 6 x$ & $138.5 \pm 6 x$ & $138.5 \pm 6 x$ \\
\hline $20^{+}$ & $37.6 \pm 2 z$ & $57.9 \pm 1 y$ & $68.9 \pm 7 x$ \\
\hline $3^{++}$ & $23.8 \pm 5 z$ & $34.4 \pm 3 y$ & $43.8 \pm 4 x$ \\
\hline \multirow[t]{2}{*}{$5^{++}$} & $10.9 \pm 1$ y & $10.8 \pm 2 y$ & $12.3 \pm 3 x$ \\
\hline & \multicolumn{3}{|c|}{$\mathrm{pH}$} \\
\hline $1^{\dagger}$ & $2.4 \pm 0.6 x$ & $2.3 \pm 0.7 x$ & $2.5 \pm 0.1 \times$ \\
\hline $20^{+}$ & $3.2 \pm 0.2 x$ & $3.1 \pm 0.1 \mathrm{y}$ & $2.9 \pm 0.2 y$ \\
\hline $3^{+\dagger}$ & $4.1 \pm 0.5 x$ & $4.1 \pm 0.1 \times$ & $3.9 \pm 0.3 y$ \\
\hline \multirow[t]{2}{*}{$5^{+t}$} & $5.2 \pm 0.1 \times$ & $5.3 \pm 0.2 x$ & $5.0 \pm 0.1 y$ \\
\hline & \multicolumn{3}{|c|}{ Acidez titulable (\% ácido cítrico) } \\
\hline $1^{\dagger}$ & $5.3 \pm 0.1 x$ & $5.2 \pm 0.1 \times$ & $5.3 \pm 0.1 \times$ \\
\hline $20^{+}$ & $3.6 \pm 0.2 z$ & $4.1 \pm 0.7 y$ & $4.8 \pm 0.3 x$ \\
\hline $3^{++}$ & $0.8 \pm 0.2 z$ & $0.9 \pm 0.2 y$ & $1.5 \pm 0.07 x$ \\
\hline \multirow[t]{2}{*}{$5^{+\dagger}$} & $0.2 \pm 0.1 y$ & $0.3 \pm 0.2 x$ & $0.3 \pm 0.1 \times$ \\
\hline & \multicolumn{3}{|c|}{ Sólidos solubles totales ( $\left.{ }^{\circ} \mathrm{Brix}\right)$} \\
\hline $1^{\dagger}$ & $3.9 \pm 0.1 \times$ & $3.8 \pm 0.10 x$ & $3.7 \pm 0.1 \times$ \\
\hline $20^{+}$ & $14.1 \pm 0.1 x$ & $13.8 \pm 0.3 x$ & $11.6 \pm 0.1 y$ \\
\hline $3^{+t}$ & $20.3 \pm 1.3 x$ & $19.3 \pm 0.1 x$ & $16.7 \pm 1.22 y$ \\
\hline $5^{++}$ & $21.3 \pm 0.2 x$ & $20.3 \pm 0.3 x$ & $19.4 \pm 0.1 y$ \\
\hline
\end{tabular}

Medias con diferente letra $(x, y, z)$ por fila son estadísticamente diferentes $(P \leq 0.05) .{ }^{\dagger}$ Mango almacenado a $13 \pm 1{ }^{\circ} \mathrm{C}$ por $20 \mathrm{~d} .{ }^{+\dagger}$ Mango almacenado a $25 \pm 2{ }^{\circ} \mathrm{C}$, previo a $20 \mathrm{~d}$ a $13 \pm 2{ }^{\circ} \mathrm{C}$.

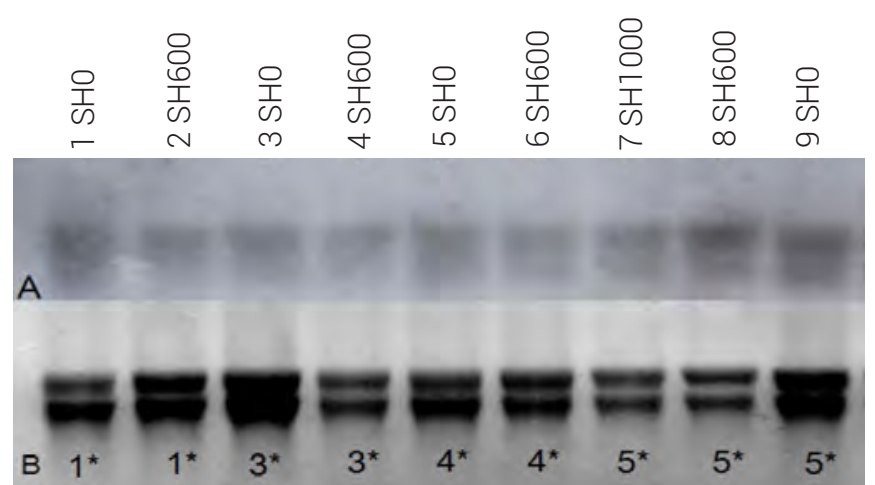

Figura 3. Ensayo de análisis Northern blot (A) del transcrito de ACC oxidasa (ACO-1) del mango var. Ataulfo testigo (SH0, carriles uno, tres, cinco y nueve), tratado con 1-MCP a $600 \mathrm{~nL} \mathrm{~L}^{-1}$ (SH600, carriles dos, cuatro, seis y ocho) y $1000 \mathrm{~nL} \mathrm{~L}^{-1}$ (SH1000, carril siete) por $24 \mathrm{~h}$ a $20 \pm 2{ }^{\circ} \mathrm{C}$. "Días uno a cinco de almacenamiento a $25^{\circ} \mathrm{C}$. Gel desnaturalizante con las mismas muestras (B). 


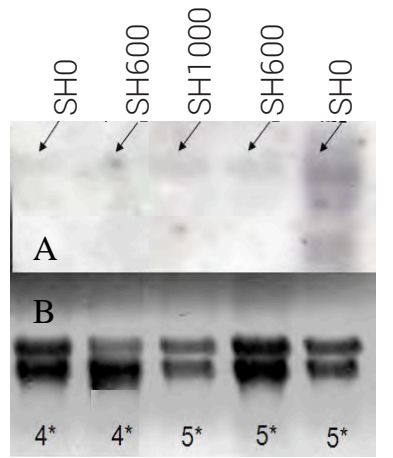

Figura 4. Ensayo de análisis Northern blot (A) del transcrito de receptor de etileno (Mi-ETR1) del mango var. Ataulfo testigo ( $\mathrm{SHO}$, carriles uno y cinco), tratado con 1-MCP a $600 \mathrm{~nL} \mathrm{~L}^{-1}$ (SH600, carriles dos y cuatro) y 1000 $\mathrm{nL} \mathrm{L} \mathrm{L}^{-1}\left(\mathrm{SH} 1000\right.$, carril tres) por $24 \mathrm{~h}$ a $20 \pm 2{ }^{\circ} \mathrm{C}$. *Días cuatro a cinco de almacenamiento a $25^{\circ} \mathrm{C}$. Gel desnaturalizante con las mismas muestras (B).

\section{AGRADECIMIENTOS}

A la empacadora "Productora Agrícola La Romera SPR de $R L$ ", especialmente al Ing. Abelardo Rodríguez, por la donación de la materia prima. Así mismo los autores agradecen al CONACyT por el financiamiento para la elaboración de esta investigación (clave no. 79905).

\section{BIBLIOGRAFÍA}

Abeles F. B., P. W. Morgan and M. Saltveit (1992) Ethylene in Plant Biology Academic Press. San Diego. USA. pp:120-181.

Amornputti S., S. Ketsa and W. G. van Doorn (2014) Effect of 1-methylcyclopropene (1-MCP) on storage life of durian fruit. Postharvest Biology and Technology 97:111-114.

AOAC (2005) Official Methods of Analysis of AOAC INTERNATIONAL (2005) 18th Ed., AOAC INTERNATIONAL, Gaithersburg, MD, USA

Asif M.H., N. Pathak, T. Solomos and P. K. Trivedi (2009) Effect of low oxygen, temperature and 1-methylcyclopropene on expression of genes that regulating ethylene biosynthesis and perception during ripening in Apple. South African Journal of Botany 75:137-144

Blankenship S. M. and J. M. Dole (2003) 1-Methylcyclopropene: a review. Postharvest Biology and Technology 28:1-25

Cua A. H. and M. C. Lizada (1990) Ethylene production in the 'Carabao' mango (Mangifera indica L.) fruit during maturation and ripening. Acta Horticulturae 269:169-179.

Gutiérrez M. P., R. López-Gómez and M. A. Gómez-Lim (2001) Identification of an ETR-1 homologue from mango fruit expressing during fruit ripening and wounding. Journal of Plant Physiology 158:104-108

Jiang L., L. Zhang, Y. Shi, Z. Lu and Z. Yu (2014) Proteomic analysis of peach fruit during ripening upon post-harvest heat combined with 1-MCP treatment. Journal of Proteomics 98:31-43.

Jung S., and C. B. Watkins (2014) Internal ethylene concentrations in apple fruit at harvest affect persistence of inhibition of ethylene production after 1-methylcyclopropene treatment. Postharvest Biology and Technology 96:1-6.

Ketsa S., S. Chidtragool, D. J. Klein and S. Lurie (1998) Ethylene synthesis in mango fruit following heat treatment. Postharvest Biology and Technology 10:2577-2581.
Khan A. S., and Z. Singh (2009) 1-MCP application suppresses ethylene biosynthesis and retards fruit softening during cold storage of 'Tegan Blue' Japanese plum. Plant Science 176:539-544.

Li F., X. Zhang, B. Song, J. Li, Z. Shang and J. Guan (2013) Combined effects of 1-MCP and MAP on the fruit quality of pear (Pyrus bretschneideri Reld Cv. Laiyang) during cold storage. Scientia Horticulturae 164:544-551.

Lizada M. C., and S. F. Yang (1979) A Simple and Sensitive Assay for 1-Aminociclopropane-1-Carboxilyc Acid. Analitical Biochemistry 100:140-145

López-Gómez R., J. L. Cabrera-Ponce, L. J. Saucedo-Arias, L. Carreto-Montoya, R. Villanueva-Arce, J. C. Díaz-Pérez, M. A. Gómez-Lim and L. Herrera-Estrella (2009) Ripening in papaya fruit altered by ACC oxidase co-suppression. Transgenic Research 18:89-97.

López-Gómez R. and M. A. Gómez-Lim (1992) A method for extracting intact RNA from fruits rich in polysaccharides using ripe mango mesocarp. HortScience 27:440-442

Ma G., R. Wang, C. Wang, M. Kato, K. Yamawaki, F. Qin and H. Xu (2009) Effect of 1-methylcyclopropene on expression of genes for ethylene biosynthesis enzymes and ethylene receptors in post-harvest broccoli. Plant Growth Regulation 57:223-232.

Montalvo G.E., H. S. García, B. Tovar and M. Mata (2007) Application of exogenous ethylene on postharvest ripening of refrigerated 'Ataulfo' mangoes. Food Science and Technology 40:1466-1472.

Muy R. D., B. E. Valenzuela and J. Siller (2009) Efecto del 1-metilciclopropeno y de una película comestible sobre la actividad enzimática y calidad poscosecha del mango 'Ataulfo'. Revista Fitotecnia Mexicana 32:53-60

Osuna G. J. A., J. A. Beltrán y M. A. Urías-López (2005) Efecto del 1-metilciclopropeno (1-MCP) sobre la vida de anaquel y calidad de mango para exportación. Revista Fitotecnia Mexicana 28:271-278.

Osuna G. J. A., I. Cáceres, E. Montalvo, M. Mata y B. Tovar (2007) Efecto del 1-metilciclopropeno (1-MCP) y tratamiento hidrotérmico sobre la fisiología y calidad del mango 'Keitt'. Revista Chapingo Serie Horticultura 13:157-163.

Osuna-García J. A., M. H. Pérez-Barraza, V. Vázquez-Valdivia and J. A. Beltrán (2009) Methylcyclopropene (1-MCP), a new approach for exporting 'Kent' mangoes to Europe and Japan. Acta Horticulturae 820:721-724.

Pereira-Bomfım M., G. P. Pereira-Lima, J. A. Rebouças-São, F. Vianello and L. Manoel de Oliveira (2011) Post-harvest conservation of 'Tommy Atkins' mangoes treated with 1-methylcyclopropene. Revista Brasileira de Fruticultura 33:290-297.

SAGARPA (2014) Secretaria de Agricultura, Ganadería, Desarrollo Rural, Pesca y Alimentación. http://www.sagarpa.gob.mx/saladeprensa/2012/Paginas/2014B289.aspx (Junio 2015)

Sambrook J. and D.W. Russell (2001) Molecular Cloning. A Laboratory Manual. 3rd ed. Cold Spring Harbor Press USA. pp:75-79.

Severo J., A. Tiecher, J. Pirrello, F. Regad, A. Latché, J. Pech, M. Bouzayen and C. V. Rombaldi (2015) UV-C radiation modifies the ripening and accumulation of ethylene response factor (ERF) transcripts in tomato fruit. Postharvest Biology and Technology 102:9-16.

Tovar B., H. S. García and M. Mata (2001) Physiology of pre-cut mango I ACC and ACC oxidase activity of slices subjected to osmotic dehydration. Food Research International 34:207-215

Tsouvaltziz P., D. Gerasopoulos and A. Siomos (2007) Effects of base removal and heat treatment on visual and nutritional quality of minimally processed leeks. Postharvest Biology and Technology 43:158-164

Villalobos-Acuna M.G., W. V. Biasi, S. Floresa, C. Z. Jiang, M. S. Reida, N. H. Willitsc and E. J. Mitcham (2011) Effect of maturity and cold storage on ethylene biosynthesis and ripening in 'Bartlett' pears treated after harvest with 1-MCP. Postharvest Biology and Technology 59:1-9

Xie X., J. Song, Y. Wang and D. Sugar (2014) Ethylene synthesis, ripening capacity and superficial scald inhibition in 1-MCP treated 'd'Anjou' pears are affected by storage temperature. Postharvest Biology and Technology 97:1-10.

Yang X., J. Song, L. Campbell-Palmer, S. Fillmore and Z. Zhang (2013) Effect of ethylene and 1-MCP on expression of genes involved in ethylene biosynthesis and perception during ripening of apple fruit. Postharvest Biology and Technology 78:55-66. 
Zhu X., L. Shen, D. Fu, Z. Si, B. Wu, W. Chen and X. Li (2015) Effects of the combination treatment of 1-MCP and ethylene on the ripening of harvested banana fruit. Postharvest Biology and Technology 107:23-32.
Zóffoli J. P. (2000) Efectividad del 1-MCP sobre la arenosidad, pardeamiento y ablandamiento de duraznos y nectarinas. Revista Platina de Chile 22:14-16. 